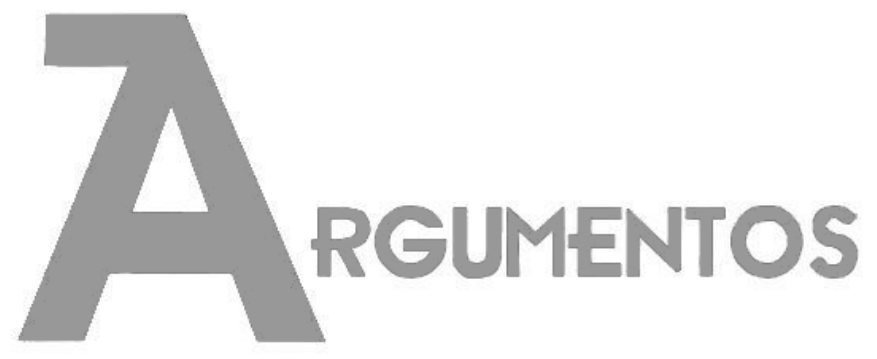

Vol. 17, n. 2, jul./dez. 2020 ISSN: 2527-2551 (online)

https://www.periodicos.unimontes.br/index.php/argumentos

\title{
Apresentação do dossiê \\ Jogos Olímpicos e Paralímpicos na contemporaneidade: uma breve revisão literária da produção científica vigente
}

\author{
Ester Liberato Pereira ${ }^{1}$ \\ Karina Barbosa Cancella ${ }^{2}$ \\ Jimmy Medeiros ${ }^{3}$
}

Recebido em: 02/07/2020

Aprovado em: $13 / 07 / 2020$

Resumo: Confere-se a denominação de 'Estudos Olímpicos' ao conjunto de estudos, de caráter acadêmico, que apresenta os Jogos Olímpicos/Paralímpicos e/ou o Movimento Olímpico/Paralímpico - em suas diferentes manifestações - como temas, lócus ou aspecto da análise dos fenômenos esportivos. Nesta direção, pretende-se elaborar um breve levantamento da literatura acerca do tema, no Brasil, no século XXI, com o objetivo de fomentar estudos que articulem as temáticas do esporte, da cultura e da sociedade, apoiadas em teorias, conceitos e metodologias das Ciências Sociais. Ao seguir tal proposta, o dossiê proporciona estudos sobre a programação cultural e artística, bem como a respeito das participações sociopolíticas e esportivas da organização de edições recentes dos Jogos Olímpicos/Paralímpicos. Também estão presentes discussões acerca da relação entre preservação e Jogos Olímpicos, do percurso e da formação em pesquisa no campo dos Estudos Olímpicos no Brasil, da introdução de atletas

\footnotetext{
${ }^{1}$ Doutora em Ciências do Movimento Humano (UFRGS), Professora do Departamento de Educação Física e do Desporto (DEFD) e do Programa de Pós-Graduação em História (PPGH) da Universidade Estadual de Montes Claros - MG (Unimontes), Brasil. Pesquisadora do Grupo de Estudos em História do Esporte e da Educação Física (GEHEF). E-mail: ester.pereira@unimontes.br. ORCID: https://orcid.org/0000-0001-61939132.

2 Doutora em História Comparada (UFRJ), Professora do Departamento de Anos Iniciais do Colégio Pedro II, Pesquisadora do SPORT - Laboratório de História do Esporte e do Lazer (UFRJ) e do LEPPAR - Laboratório de Estudos, Pesquisas e Práticas Pedagógicas Antirracistas (Colégio Pedro II), Brasil. E-mail: karinacancella@gmail.com. ORCID: https://orcid.org/0000-0003-4012-2013.

${ }^{3}$ Doutor em Políticas Públicas (UFRJ), Pesquisador da Fundação Getulio Vargas, Coordenador de Ensino de Graduação da Escola de Ciências Sociais FGV CPDOC e Professor do Programa de Pós-graduação em História, Política e Bens Culturais, Brasil - jimmy.medeiros@fgv.br. ORCID: https://orcid.org/0000-00028280-3338.
} 
Dossiê | Apresentação do dossiê "Jogos Olímpicos e Paralímpicos na contemporaneidade: uma breve revisão literária da produção científica vigente” (PEREIRA, Ester Liberato Pereira; CANCELLA, Karina Barbosa Cancella; MEDEIROS, Jimmy)

da seleção brasileira feminina de voleibol sentado na prática esportiva paralímpica, além de um debate historiográfico sobre a pesquisa em história do esporte. Conta-se ainda com demais questões de equivalente importância, apreciações que se tornam ainda mais relevantes diante de um cenário em que o esporte brasileiro depende quase que inteiramente de dinheiro público. Palavras-chave: Jogos Olímpicos; Jogos Paralímpicos; Megaevento esportivo; Legados esportivos; Políticas de esporte.

\section{Presentación del dossier \\ Juegos Olímpicos y Paralímpicos contemporáneos: una breve revisión literaria de la producción científica actual}

Resumen: El término 'Estudios Olímpicos' se le da al conjunto académico de estudios, que presenta los Juegos Olímpicos/Paralímpicos y/o el Movimiento Olímpico/Paralímpico - en sus diferentes manifestaciones - como temas, locus o aspectos del análisis de fenômenos deportivos. En esta dirección, se pretende elaborar una breve investigación bibliográfica sobre el tema en Brasil em el siglo XXI, com el objetivo de promover estudios que articulenlos temas del deporte, la cultura y la sociedade basados em teorías, conceptos y metodologías de las Ciencias Sociales. Siguiendo esta propuesta, el dossier proporciona estudios sobre programación cultural y artística, así como sobre la participación sociopolítica y deportiva de la organización de ediciones recientes de los Juegos Olímpicos/Paralímpicos. También hay discusiones sobre la relación entre la preservación y los Juegos Olímpicos, el curso y el entrenamiento de investigación en el campo de los Estudios Olímpicos en Brasil, la introducción de atletas del equipo de voleibol sentado femenino brasileño en los deportes paralímpicos, además de un debate historiográfico sobre investigación en historia del deporte. Todavía hay otros temas de importancia equivalente, apreciaciones que se vuelven aún más relevantes frente a um escenario en el que el deporte brasileño depende casi por completo del dinero público.

Palabras clave: Juegos Olímpicos; Juegos paralímpicos; Mega evento deportivo; Legados deportivos; Políticas deportivas.

\section{Presentation of the special issue \\ Contemporary Olympic and Paralympic Games: a brief literary review of current scientific production}

Abstract: The term 'Olympic Studies' is given to the set of studies, of an academic nature, which presents the Olympic/Paralympic Games and/or the Olympic/Paralympic Movement - in its different manifestations - as themes, locus or aspect of the analysis of sports phenomena. In this direction, we intend to elaborate a brief survey of the literature on the subject, in Brazil, in the 21st century, with the objective of promoting studies that articulate the themes of sport, culture and society based on theories, concepts and methodologies of Social Sciences. Following this proposal, the special issue provides studies on cultural and artistic programming, as well as on the socio-political and sports participation of the organization of recent editions of the Olympic/Paralympic Games. There are also discussions about the relationship between preservation and the Olympic Games, the course and research training in the field of Olympic Studies in Brazil, the introduction of athletes from the Brazilian women's sitting volleyball team in Paralympic sports, in addition to a historiographical debate about research in sports history. There are also other issues of equal importance, appraisals that become even more relevant in the face of a scenario in which Brazilian sport depends almost entirely on public money.

Keywords: Olympic Games; Paralympic Games; Sports mega event; Sporting legacies; Sport policies. 
Dossiê | Apresentação do dossiê "Jogos Olímpicos e Paralímpicos na contemporaneidade: uma breve revisão literária da produção científica vigente" (PEREIRA, Ester Liberato Pereira; CANCELLA, Karina Barbosa Cancella; MEDEIROS, Jimmy)

Estas considerações iniciais apresentam, como objetivo, expor, em linhas gerais, um breve e conciso levantamento da literatura acerca dos Estudos Olímpicos, no Brasil, no século XXI, com o intuito de fomentar estudos que articulem as temáticas do esporte, da cultura e da sociedade apoiadas em teorias, conceitos e metodologias das Ciências Sociais. Nesta direção, não se submergirá nas sinuosidades atinentes ao que se tem denominado como "Estudos Olímpicos" e que se colocam em um viés interdisciplinar. Assim, apesar deste campo do conhecimento não se valer, exclusivamente, das teorias das Ciências Sociais, mas, sim, agregar a Psicologia, a Pedagogia, a História, a Administração, a Educação Física, a Filosofia, etc., não se almeja contemplá-las aqui. 0 nosso intuito é o de que as leitoras e os leitores possam ter uma ideia inicial das especificidades de possíveis abordagens metodológicas e teóricas acerca de um conjunto de estudos os quais, sob a perspectiva das Ciências Sociais, possuem, como enfoque, o Esporte Olímpico/Paraolímpico, o Movimento Olímpico, os Jogos Olímpicos/Paralímpicos e o Olimpismo.

Ao considerar, assim, o campo de formação dos três autores desta apresentação (uma com formação em Educação Física, uma com formação em História e um com formação em Ciências Sociais), gostaríamos de aclarar que nosso intuito, aqui, é proporcionar uma contribuição à área de Ciências Sociais, no conjunto de pesquisas que compõem os Estudos Olímpicos. Portanto, a partir de nossas distintas e interdisciplinares experiências neste cenário, tais como a composição da Academia Olímpica Brasileira, formação em Estudos Olímpicos pela Academia Olímpica Internacional (Olympia - Grécia), bem como projetos de pesquisa executados na área, apontamos nossos vieses e deixamos claro nosso campo de partida, o que pode auxiliar as leitoras e os leitores a compreenderem nossas escolhas para compor o presente dossiê e para escrever este texto introdutório.

O convite para constituirmos um dossiê para o periódico Argumentos para o segundo semestre de 2020 deu-se em meados de 2018. Em função de nossos percursos acadêmicos e de nosso campo de investigação, bem como da proximidade de uma nova edição dos Jogos Olímpicos ${ }^{4}$ e Paralímpicos, a questão destes megaeventos esportivos e do Movimento Olímpico foi, com certeza, determinada como o embasamento

\footnotetext{
${ }^{4}$ Atualmente, os Jogos Olímpicos de verão compõem o megaevento de maior porte em escala mundial, abarcando mais da metade da população do planeta em sua audiência (DACOSTA, 2007).
} 
Dossiê | Apresentação do dossiê "Jogos Olímpicos e Paralímpicos na contemporaneidade: uma breve revisão literária da produção científica vigente” (PEREIRA, Ester Liberato Pereira; CANCELLA, Karina Barbosa Cancella; MEDEIROS, Jimmy)

primordial que orientaria esta publicação. Portanto, à época, ainda não fazíamos ideia de que os Jogos seriam adiados para 2021 por conta da pandemia do novo coronavírus (2019-nCoV).

Ao ceder à pressão do mundo esportivo, o premiê Shinzo Abe chegou a um acerto para a alteração da data com o presidente do Comitê Olímpico Internacional (COI), Thomas Bach. Isto, principalmente, porque, no período previsto de acontecimento dos jogos, em 2020, a pandemia poderia estar em regressão em determinados países e ascensão em outros, e isso foi levado em consideração como um fator de risco. Nesta direção, assim como Guerreiro et al (2020), avaliamos que a tomada de decisão de adiar os Jogos Olímpicos e Paralímpicos de Tóquio 2020 para o ano de 2021, em função do 2019-nCoV, foi adequada e de extrema relevância para poupar a saúde de atletas olímpicos e paralímpicos, bem como de espectadores.

Contudo, assim como o nome dos megaeventos foi mantido (Jogos Olímpicos e Paralímpicos 2020), nosso dossiê também seguiu seu plano e curso original. Compreendemos que os Estudos Olímpicos, como ponto central, ainda seguiam muito vastos e capazes de, realmente, compor um dossiê que proporcionasse um aporte nessa área de pesquisa. Isto porque, afora estar disposto ainda em um cenário de desenvolvimento na academia brasileira, este campo apresenta-se com uma condição cada vez mais sistematizada, continuada e acadêmica. Considere-se que observamos a existência de cerca de 10 grupos de pesquisa direcionados para investigações olímpicas/paraolímpicas cadastrados no Diretório dos Grupos de Pesquisa no Brasil Lattes do Conselho Nacional de Desenvolvimento Científico e Tecnológico (CNPq). Tais grupos participam de fóruns olímpicos/paraolímpicos das mais diversas áreas de estudos.

Afinal, inserida em um modelo de comparação internacional, a Academia Olímpica Brasileira coloca a produção acadêmica nacional dentre as cinco mais importantes globalmente, provavelmente ainda atrás da produção dos estudos estadunidenses, da tradição das academias alemã e britânica e da produção australiana mais atual. Contudo, esta colocação deve apresentar consequências efetivas a partir desta ocasião histórica importante no campo esportivo brasileiro. Ao sediar megaeventos como os XV Jogos Pan-americanos e Parapan-Americanos (Rio 2007), os Jogos Mundiais Militares (Rio 2011), a Copa das Confederações da FIFA (Brasil 2013), a 
Dossiê | Apresentação do dossiê "Jogos Olímpicos e Paralímpicos na contemporaneidade: uma breve revisão literária da produção científica vigente" (PEREIRA, Ester Liberato Pereira; CANCELLA, Karina Barbosa Cancella; MEDEIROS, Jimmy)

Copa do Mundo de Futebol da FIFA (Brasil 2014) e os Jogos Olímpicos e Paralímpicos (Rio 2016), o país, que já contava com uma academia olímpica nacional desde 1989, passou a apresentar programas de educação olímpica mais sistemáticos. Nesta direção, o esporte recebe um novo entendimento e redimensionamento no momento histórico em curso e alcança novos espaços de debate.

Para apreendermos melhor esta ampla conjuntura em que distintas perspectivas e relações se combinam, abrimos este artigo com uma concisa revisão de literatura acerca do tema, no Brasil, no século XXI, com o objetivo de fomentar estudos que articulem as temáticas do esporte, da cultura e da sociedade apoiadas em teorias, conceitos e metodologias das Ciências Sociais. Apesar disso, salientamos que não procuramos, com essa revisão, esgotar as possibilidades teóricas, conceituais e metodológicas, mas somente expor um breve cenário histórico e como os Estudos Olímpicos foram se tornando foco de atenção em si mesmos. Depois dessa revisão literária, realizamos uma exposição de parte da conjuntura brasileira e a emergência dos Estudos Olímpicos para, com isso, atentarmos para como o esporte e o fenômeno olímpico/paralímpico se colocam como objeto e como ponto de partida de investigação e teorização pelas Ciências Sociais.

De forma tradicional, tanto no Brasil quanto no exterior, o desenvolvimento de estudos a propósito do esporte no campo das Ciências Sociais e Humanas tem amparado, nos últimos 40 anos, a conformação de uma distinção epistemológica entre Estudos Olímpicos e Olimpismo. O primeiro remete-se a uma estratégia de enfoque para a produção científica sobre manifestações olímpicas/paralímpicas, enquanto o segundo acena aos alicerces e valores que justificam e dirigem a atuação dos indivíduos acoplados ao esporte em seus diversos níveis. Tal distinção, contudo, ainda não constitui uma concordância absoluta (DACOSTA, 2007; RUBIO et al., 2007).

Desta forma, observa-se o mesmo fenômeno no Brasil. Contudo, possivelmente em função do desenvolvimento acadêmico bastante mais recente dos Estudos Olímpicos no país, constata-se ainda, por vezes, o uso indistinto dos termos com um nível maior de intensidade. De tal modo, no Brasil, ainda pode identificar-se o uso do termo Olimpismo para assinalar tanto os estudos acerca dos Valores Olímpicos quanto as pesquisas a propósito do esporte e da Educação Física apresentando, como referência, o Movimento Olímpico (TAVARES et al., 2005). 
Dossiê | Apresentação do dossiê "Jogos Olímpicos e Paralímpicos na contemporaneidade: uma breve revisão literária da produção científica vigente” (PEREIRA, Ester Liberato Pereira; CANCELLA, Karina Barbosa Cancella; MEDEIROS, Jimmy)

Isto porque, no Brasil, a própria procedência dos Estudos Olímpicos é insuficientemente discernível do desenvolvimento do próprio Movimento Olímpico. Desta forma, uma vez que o desenvolvimento deste Movimento, no país, possuía, até a refundação do Comitê Olímpico Brasileiro (COB), em 1935, um caráter aleatório, o estudo e mesmo a noção da Ideia Olímpica eram, virtualmente, desconhecidos e fundavam-se, quando muito, no empenho e na ação de sujeitos e não de instituições. Nesta conjuntura, a função dos jornalistas na divulgação do Olimpismo, no país, parece ser maior do que o hoje considerado. De fato, o jornalista Tomás Mazzoni, por exemplo, com sua coluna no jornal A Gazeta (SP), desde os anos de 1920 e 1930, a qual assinava sob o pseudônimo 'Olympicus', pode ser considerado um dos precursores no Brasil (TAVARES et al., 2005).

Este, por sua vez, consiste na

ação, concertada, organizada, universal e permanente, de todos os indivíduos e entidades que são inspirados pelos valores do Olimpismo, sob a autoridade suprema do Comitê Olímpico Internacional (COI). Estende-se aos cinco continentes e atinge o seu auge com a reunião de atletas de todo o mundo no grande festival desportivo que são os Jogos Olímpicos. O seu símbolo é constituído por cinco anéis entrelaçados (IOC, 2010).

Quanto aos Jogos Olímpicos/Paralímpicos, estes são mais do que meramente eventos esportivos internacionais propostos para congregar a nata dos esportistas de um conjunto determinado de modalidades esportivas a cada quatro anos em uma cidade distinta. De fato, os Jogos possuem significado histórico e político afora ainda constituírem um fenômeno cultural e econômico (TAVARES, 2005).

Depois desta assimilação terminológica e contextualizando o país após os eventos esportivos que recepcionou, o empenho pelo objeto de estudo adquire uma importância significativa. Uma vez que se trata de uma questão da contemporaneidade e foco de investigação de diferentes campos acadêmicos, os Estudos Olímpicos apresentam um desenvolvimento e a concepção de possibilidades inovadoras de pesquisa para os(as) interessados(as).

Essa múltipla abordagem por distintas comunidades epistemológicas fica evidente na avaliação da literatura sobre Estudos Olímpicos. Encontramos trabalhos sobre distintos temas, diferentes abordagens metodológicas e diferenciados 
Dossiê | Apresentação do dossiê "Jogos Olímpicos e Paralímpicos na contemporaneidade: uma breve revisão literária da produção científica vigente” (PEREIRA, Ester Liberato Pereira; CANCELLA, Karina Barbosa Cancella; MEDEIROS, Jimmy)

arcabouços teóricos, contudo, sempre conectados pelo objeto dos Jogos Olímpicos. Essa multiplicidade é importante, sobretudo, pela sua amplitude e pelo grau de complexidade do tema, permitindo análises complementares e que favorecem um melhor entendimento do objeto.

O livro "Qual legado: leituras e reflexões sobre os Jogos Olímpicos Rio 2016", publicado em 2018, possibilita uma amostra desta perspectiva multidisciplinar, pois reúne uma coletânea de análises sobre o desejado legado olímpico por perspectivas da área da educação, do jornalismo e comunicação, da sociologia, história, administração, relações internacionais, políticas públicas e ciência política, por exemplo. Portanto, agrupou pesquisadores de campos diferentes e de três países; todavia, todos tinham, em comum, a ênfase na edição brasileira dos Jogos Olímpicos e Paralímpicos como elemento central da análise (MARQUES; ROCCO JÚNIOR, 2018).

Mais um livro, "Múltiplos olhares sobre os Jogos Olímpicos", também publicado em 2018, destaca-se pela sua proposta de arquitetar uma visão plural a propósito dos Jogos Olímpicos. Foram reunidos, neste, pesquisadores brasileiros fundamentais que estudam este objeto. Os Jogos Olímpicos atuam como linha de sustentação do livro como um todo. As diversas visões foram desenvolvidas, por meio de 10 capítulos, por distintos campos (Sociologia, Geografia, Antropologia, História e Educação Física), apresentando, como enfoque, assuntos, em geral, ainda pouco investigados pelos pesquisadores (GIGLIO et al., 2018).

Outro destaque recente de pesquisa acadêmica sobre Estudos Olímpicos é o projeto "Preservação da Memória das Olimpíadas: processos e ações" ${ }^{5}$, gerido pela Fundação Casa de Rui Barbosa, com a realização em parceria com a Escola de Ciências Sociais FGV CPDOC. O objetivo principal foi constituir um repositório de acervo sobre a memória da organização dos Jogos Olímpicos e Paraolímpicos da edição de 2016 para garantir fontes de informações para futuros pesquisadores, em perspectiva restrita à academia, bem como de outros interessados, em uma abordagem mais ampla. De interessante, o projeto considerou o período compreendido "desde a candidatura do Rio de Janeiro à cidade-sede até a conclusão do evento e a discussão de seus impactos e legados". O projeto resultou na organização de um evento acadêmico, na publicação

\footnotetext{
${ }^{5}$ Mais informações em: http://memoriadasolimpiadas.rb.gov.br/apresentacao.htm.
} 
Dossiê | Apresentação do dossiê "Jogos Olímpicos e Paralímpicos na contemporaneidade: uma breve revisão literária da produção científica vigente” (PEREIRA, Ester Liberato Pereira; CANCELLA, Karina Barbosa Cancella; MEDEIROS, Jimmy)

de dois livros e de um portal na internet para disseminar grande parte do conteúdo produzido em um ambiente on-line, facilitando o acesso dos interessados.

Esta análise, adicionalmente, também pode ser feita, por meio da avaliação dos grupos de estudo nacionais que se propõem a pesquisar este objeto, conforme o Diretório de Grupos de Pesquisa no Brasil Lattes - CNPq são: ARETE - Centro de Estudos Olímpicos (UFES); Centro de Estudos Olímpicos e Paraolímpicos (UFRGS); GPEOP Grupo de Pesquisa em Estudos Olímpicos e Paraolímpicos (UFS), Grupo de Estudos e Pesquisas em Gestão Esportiva - GEPEGE - (UNESP), Grupo de Estudos Olímpicos (USP); Grupo de Pesquisa em Estudos Olímpicos (PUCRS); NEHME - Núcleo de Estudos em História do Esporte e da Educação Física (UFRGS); Núcleo de Estudos Educação Física, Corpo e Sociedade (UFJF); e NUPAFISE - Núcleo de Pesquisa em Aptidão Física, Saúde e Desempenho de Sergipe (UFS).

A relevância de tais grupos de estudos e pesquisas reside no fato de contribuírem para a pulverização dos conhecimentos produzidos na área dos Estudos Olímpicos, seja por meio de suas inúmeras investigações e atuações, as quais colaboram para preservar uma memória do esporte olímpico nacional, seja por meio da promoção à educação olímpica no Brasil. O planejamento de grupos de trabalho e de eventos acadêmicocientíficos, tais como o Seminário de Estudos Olímpicos, o qual ocorre desde 2005 e, em 2019, teve sua 9a edição, promovido pelo Grupo de Estudos Olímpicos da Escola de Educação Física e Esporte da Universidade de São Paulo (USP), também contribuem e enriquecem as discussões nacionais e internacionais. Este referido grupo de estudos ainda conta com sua líder, a Profa. Katia Rubio, à frente da equipe editorial do Olimpianos - Journal of Olympic Studies, o qual consiste em mais uma importante e estratégica ferramenta para o desenvolvimento da área dos Estudos Olímpicos, uma vez que se trata de um periódico destinado à publicação de investigações e estudos relacionados a temas olímpicos e paralímpicos.

Vale a ressalva, assim, que, dentre os nove grupos localizados pelo diretório, oito encontram-se na área predominante de Educação Física e apenas um na área predominante de Psicologia, não havendo registros oficiais, no CNPq, até o momento, de grupos de pesquisa de Estudos Olímpicos na área predominante de Ciências Sociais e/ou Humanas. Afora os grupos, é possível listar alguns (algumas) atuantes autores(as) e estudiosos(as) do campo, como Alberto Reppold Filho, Ana Miragaya, Janice Zarpellon 
Dossiê | Apresentação do dossiê "Jogos Olímpicos e Paralímpicos na contemporaneidade: uma breve revisão literária da produção científica vigente” (PEREIRA, Ester Liberato Pereira; CANCELLA, Karina Barbosa Cancella; MEDEIROS, Jimmy)

Mazo, Katia Rubio, Lamartine Pereira DaCosta, Leonardo Mataruna, Luis Henrique Rolim, Nelson Todt, Otávio Tavares e Roberto Mesquita, entre outros. As publicações a respeito dos Estudos Olímpicos, no país, são relativamente atuais e nota-se uma literatura crescente, apesar de ainda limitada, sobre investigações acerca do tema publicadas em periódicos científicos. Desta forma, tem-se que a divulgação dos Estudos Olímpicos, no país, tem acontecido, com maior intensidade, na configuração de ensaios publicados em livros e capítulos de livros do que como artigos científicos divulgados em periódicos.

Outra perspectiva de analisar este campo de estudo no âmbito das ciências sociais é através dos trabalhos apresentados nos Grupos de Trabalhos (GT) dos encontros da Associação Nacional de Pós-graduação e Pesquisa em Ciências Sociais (ANPOCS), o principal evento acadêmico brasileiro da área. Um primeiro dado, não é comum a disponibilidade de GTs de esporte na ANPOCS. Por exemplo, na 44a edição, a ser realizada em 2020, não há uma opção para pesquisadores debaterem este tema em um GT. Gastaldo (2011), em paper apresentado na 35a edição da ANPOCS, detalha a ocorrência do GT “Esporte, Política e Cultura”, em 2002 e 2003, todavia há uma descontinuidade em 2004 e 2005. Em 2006 e 2007 o GT ocorre, já no embalo do início da década dos megaeventos esportivos no Brasil. Todavia, o GT foi desfeito em 2008 e 2009, retornando em 2010 com o nome de "Esporte e sociedade", criando um novo espaço para o debate acadêmico que permaneceu até 2013. Desde então, mesmo em ano de Copa do Mundo e Jogos Olímpicos, não teve espaço dedicado estritamente ao debate do tema, sendo feito sempre que possível em um grupo de trabalho com abordagem mais ampla.

Uma outra forma de explorar o desenvolvimento de pesquisas acadêmicas sobre o tema é por meio da análise das teses e dissertações defendidas no país. Por esta linha de abordagem, uma busca no portal "Catálogo de Teses e Dissertações" ${ }^{6 "}$ da Coordenação de Aperfeiçoamento de Pessoal de Nível Superior (CAPES) permite obter uma visão panorâmica da produção recente.

\footnotetext{
${ }^{6}$ O portal foi criado pela Capes em 2002 e, logo em seguida, fez-se um esforço para inserir resumo das teses e dissertações defendidas entre 1996 e 2001. Em outro momento, o esforço foi para incluir os trabalhos defendidos desde 1987. Atualmente, a Capes atualiza o sistema anualmente com os novos trabalhos, segundo o informe de atividades pelos programas de pós-graduação do país à Capes.
} 
Dossiê | Apresentação do dossiê "Jogos Olímpicos e Paralímpicos na contemporaneidade: uma breve revisão literária da produção científica vigente" (PEREIRA, Ester Liberato Pereira; CANCELLA, Karina Barbosa Cancella; MEDEIROS, Jimmy)

À primeira vista, a produção acadêmica sobre Jogos Olímpicos tem grandes dimensões, afinal, a consulta ${ }^{7}$ no portal retornou 341 dissertações e 147 teses. Adicionalmente, a pesquisa possibilita reforçar o argumento de que este tema é objeto de pesquisa em múltiplas áreas do conhecimento na academia brasileira, visto que este total engloba as diversas áreas, como a educação física, a educação e a geografia, os principais responsáveis quantitativos de trabalhos de conclusão de cursos de mestrado e doutorado sobre este tema no Brasil.

Com a aplicação de recursos de filtragem para refinar a busca, segundo as áreas do conhecimento de interesse desta análise, encontramos 30 trabalhos defendidos no âmbito de programas de pós-graduação das Ciências Sociais - em "Sociologia", "Antropologia e Arqueologia" e "Ciência Política e Relações Internacionais" -, portanto, elas englobam aproximadamente $5 \%$ da produção total no âmbito da pós-graduação.

Seguindo a análise somente com este conjunto, o "Catálogo de Teses e Dissertações" retorna, como produção mais antiga, uma tese de doutorado defendida em 2005 na Sociologia da UNB, a qual abordou a estruturação do vôlei de praia no Brasil, como objeto de pesquisa. Decerto que outras teses e dissertações sobre Jogos Olímpicos - de forma direta ou indireta - foram elaboradas antes desta data, porém este portal da Capes foi criado apenas em 2002 e este pode ser o motivo da falta de trabalhos mais antigos. Para nossa surpresa, entre 2005 e 2011 verificamos um hiato, pois não encontramos trabalhos defendidos durante este período. Isso se deve, sobretudo, pelo uso dos termos nas consultas para esta análise. Afinal, uma tese ou dissertação só retornaria nesta pesquisa caso o termo pesquisado fosse utilizado ou no título do trabalho, ou no resumo dele. Apesar disso, um dado positivo é que desde 2011, em todos os anos tivemos teses e/ou dissertações concluídas em vários programas de pósgraduação (PPG) pelo Brasil.

No que concerne à abrangência geográfica, verificamos pesquisas sobre esportes olímpicos defendidas em PPGs nas regiões Sul, Sudeste e Centro-Oeste. Rio de Janeiro é o grande centro analítico do tema, com o maior volume de trabalhos, talvez pela capital fluminense ter sido cidade sede de todos os principais megaeventos ocorridos no Brasil no século XXI.

\footnotetext{
${ }^{7}$ Para efetuar o mapeamento, foram utilizadas quatro palavras-chaves: olimpismo, olímpicos, olímpico e olimpíadas.
} 
Dossiê | Apresentação do dossiê "Jogos Olímpicos e Paralímpicos na contemporaneidade: uma breve revisão literária da produção científica vigente" (PEREIRA, Ester Liberato Pereira; CANCELLA, Karina Barbosa Cancella; MEDEIROS, Jimmy)

As instituições de ensino superior (IES) públicas são as principais referências neste tipo de produção acadêmica, principalmente, por sediarem grande maioria dos Programas de Pós-graduação no país. A Universidade do Estado do Rio de Janeiro, a Universidade Federal Fluminense e a Universidade de São Paulo têm maior destaque, somando 12 casos. Dentre as IES privadas, com 4 casos, encontramos PUC, FGV e Unieuro.

Ademais, a pesquisa retornou programas denominados como Ciências Sociais os mais comuns (7 casos), seguido por Sociologia (5 casos) e Antropologia/Antropologia Social (5 casos). Há ainda uma tese defendida no programa Sociologia e Antropologia, uma conexão entre estas duas áreas. Não menos importantes, Ciências Militares e Ciências Aeroespaciais, juntas somam outros 5 casos, com análises típicas ao campo das relações internacionais e da ciência política. Estes dois juntos reúnem mais 4 teses/dissertações. Por fim, temos outros 3 trabalhos em História e em Direitos Humanos, Cidadania e Violência.

Há uma diversidade de temas no conjunto de trabalhos analisados. Dentre os temas analisados, é possível destacar enfoque crítico às remoções, às condições de habitação e moradia. Além disso, planejamento urbano e análise sobre novas formas de gestão pública como o projeto Porto Maravilha tiveram a atenção na pós-graduação. Ademais, há análises sobre as representações das ideias e dos discursos para o megaevento, bem como sobre as relações intergovernamentais. A pesquisa permitiu encontrar trabalhos com foco no legado olímpico, abordando o Parque Madureira e o Parque Olímpico de Deodoro, por exemplo. Ao mesmo tempo, também foram encontradas teses e dissertações sobre atividades esportivas olímpicas em centros de treinamentos, além de análises a respeito do papel da mulher no esporte.

Apesar disto, a Sociologia, por exemplo, ocupa-se do esporte desde o século XIX, buscando adiantar-se na reflexão a respeito de aspectos como sua ascendência, relevância e as relações culturais, de poder e religiosas que o permeiam. Nesta relação, o campo da Sociologia tanto provê contribuições para a Sociologia do Esporte, quanto recebe aportes dela para suas diferentes disciplinas temáticas (PILZ, 1999).

Desta forma, as mudanças sociais do fenômeno esportivo e os impactos ou relações dele com os costumes dos sujeitos inseridos neste meio, isto é, as interrelações entre a revelação do acontecimento esportivo e a sociedade é que compõem 
Dossiê | Apresentação do dossiê "Jogos Olímpicos e Paralímpicos na contemporaneidade: uma breve revisão literária da produção científica vigente” (PEREIRA, Ester Liberato Pereira; CANCELLA, Karina Barbosa Cancella; MEDEIROS, Jimmy)

o objeto de estudo deste campo científico. Faz-se relevante analisar, então, nessa direção, que, enquanto objeto de estudo, o esporte apresenta seu desenvolvimento, princípios e realizações acoplados à sociedade em que se implanta, isto é, consiste em uma prática que necessita ser contextualizada no período e no ambiente da sua socialização. É neste processo que o trabalho de Marques et al. (2009) apresenta uma importante contribuição ao pesquisar, com base em um referencial teórico vinculado às Ciências Humanas, mais exatamente à Sociologia do Esporte, as relações estruturais, históricas e comerciais entre o esporte olímpico e o esporte paralímpico e a sociedade. Dentre outras considerações, os autores identificaram que, enquanto os Jogos Olímpicos afrontam um colapso na preservação de seus ideais, ameaçados de desabar no esquecimento pela atuação do esporte-espetáculo, o imperativo urgente de conquistas e, especialmente, de lucros, o esporte paralímpico deve alargar sua divulgação e geração de recursos financeiros, para expandir sua presença na sociedade contemporânea.

De todo modo, vivemos, atualmente, uma ocasião histórica importante no campo esportivo, no país, já que o Brasil sediou amplos eventos, já referidos previamente neste texto. Tais eventos esportivos têm projetado o país no panorama mundial e estabelecido relações com a formulação de políticas públicas para o esporte no Brasil (MASCARENHAS, 2012).

É nesta perspectiva que recebe importância o dossiê que proporcionamos ao público leitor da Revista Argumentos, certos de que encontrarão, nos artigos aqui agrupados, uma extensa e multifacetada proposta de apreciações acerca de conjunturas e reflexões a propósito do esporte e dos Estudos Olímpicos, suas potencialidades e demarcações, em especial sob o ponto de vista das Ciências Sociais. Desta forma, as mudanças sociais do fenômeno esportivo e as repercussões ou relações dele com os costumes dos sujeitos que se inserem neste meio, isto é, as interdependências entre a expressão do acontecimento esportivo e a sociedade, compõem o objeto deste campo de conhecimento (MARQUES et al., 2009). O dossiê consiste, assim, em seu arranjo, de cinco artigos e uma entrevista, transcorrendo múltiplos assuntos abarcados pela área dos Estudos Olímpicos.

O trabalho de Juliana Carneiro explora o programa cultural e artístico dos Jogos Olímpicos do Rio de Janeiro, de 2016, desde o processo de candidatura, analisando a 
Dossiê | Apresentação do dossiê "Jogos Olímpicos e Paralímpicos na contemporaneidade: uma breve revisão literária da produção científica vigente” (PEREIRA, Ester Liberato Pereira; CANCELLA, Karina Barbosa Cancella; MEDEIROS, Jimmy)

centralidade da questão cultural na narrativa que abordou o megaevento como excelente ocasião para expor, ao nível mundial, a diversidade e a potência das manifestações culturais nacionais. A ação de preparação e cumprimento do Programa de Cultura dos Jogos Rio 2016 foi considerada a partir de determinadas questões: O que estava previsto no Dossiê de Candidatura como programa de cultura dos Jogos Olímpicos Rio 2016? Como foi o processo de governança da área cultural? Como a trajetória do programa de cultura dos Jogos Olímpicos Rio 2016 dialogava com a realidade das políticas públicas vigentes?

O artigo de Michel Raspaud desenvolve uma síntese histórica detalhada da escolha de Paris como cidade sede para a edição dos Jogos Olímpicos e Paralímpicos de 2024. O autor apresenta as disputas e tensões ocorridas entre instituições e agentes políticos a respeito das quatro candidaturas formalizadas junto ao $\mathrm{COI}$, sendo três tentativas fracassadas - para as edições de Barcelona 1992, Pequim 2008, Londres 2012 - e a tentativa bem-sucedida. Adicionalmente, Raspaud ilustra o debate que suscitou dúvidas entre a realização da Exposição Mundial e a das Olimpíadas. O autor demonstra como ouve uma confluência de interesses entre membros do mundo político, do Comitê Nacional Olímpico e do movimento esportivo em favor dos Jogos Olímpicos e Paralímpicos. Naquele país, a realização do megaevento esportivo é tratada como um mecanismo de impulsionamento econômico e turístico e, por conta disso, diversos eventos esportivos de alcance internacional têm sido organizados no território francês.

O artigo elaborado por Bernardo Borges Buarque de Hollanda e Vivian Luiza Fonseca aborda a relação entre preservação e Jogos Olímpicos, abordando o caso brasileiro. Para isso, os autores examinam uma iniciativa institucional de salvaguarda dos registros dos acontecimentos da Rio 2016, projeto inédito na América Latina. Assim, o detalhamento das atividades desempenhadas pela Fundação Casa de Rui Barbosa, em cooperação com a Escola de Ciências Sociais FGV CPDOC, no âmbito de um projeto voltado para criar um acervo da memória Olímpica do Rio de Janeiro. Como informado pelos autores, a FCRB "desenvolveu um amplo programa de acompanhamento e cobertura dos Jogos durante o ano de sua realização". Além disso, os autores abordam o trabalho das duas instituições para a criação de um acervo de entrevistas com base em metodologia de História Oral, bem como a difusão do conteúdo por meio de um portal da internet e um documentário. Por fim, ainda no âmbito da memória olímpica, 
Dossiê | Apresentação do dossiê "Jogos Olímpicos e Paralímpicos na contemporaneidade: uma breve revisão literária da produção científica vigente" (PEREIRA, Ester Liberato Pereira; CANCELLA, Karina Barbosa Cancella; MEDEIROS, Jimmy)

o artigo traz um detalhamento analítico da exposição "Rio de Janeiro - cidade esportiva, cidade olímpica" para demostrar como o conteúdo de jornais e revistas ilustradas podem ser úteis para evidenciar "vínculos" entre a história republicana, competições esportivas no Brasil e a possibilidade de construção de um lugar de memória olímpica para o Rio de Janeiro.

Já a entrevista de Raquel Valente de Oliveira e Tuany Defaveri Begossi com Luis Henrique Rolim aborda o percurso e a formação deste pesquisador no campo dos Estudos Olímpicos no Brasil, explorando pontos acerca de seu envolvimento com os Jogos Olímpicos, durante os quais atuou em distintas conjunturas e posições. A filosofia e os valores do Olimpismo consistem em linhas norteadoras da narrativa do entrevistado, que explora a ação da história e da cultura na constituição de narrativas esportivas no domínio Olímpico. Seu relato anuncia os significados e os sentidos do Movimento Olímpico para a conquista do direito das pessoas à prática esportiva. No viés de políticas públicas e de investimento financeiro ao esporte, Luis Henrique Rolim aborda as interconexões: esporte de alto rendimento ou esporte para todos(as)? As narrativas do entrevistado corroboram aspectos históricos e socioculturais do esporte Olímpico nos panoramas nacional e internacional, despontando representações arquitetadas ao longo de trajetória pessoal e profissional.

O trabalho de Vitória Crivellaro Sanchotene, Giandra Anceski Bataglion e Janice Zarpellon Mazo, por sua vez, apura como aconteceu a introdução de atletas da seleção brasileira feminina de voleibol sentado na prática esportiva paralímpica. Para tanto, a coleta de dados foi concretizada por meio de entrevistas semiestruturadas com cinco atletas que participaram dos Jogos Paralímpicos nas edições de 2012, em Londres, e de 2016, no Rio de Janeiro. As autoras demonstraram que a entrada das atletas na prática do voleibol sentado foi intermediada por sugestões de profissionais da área da saúde e do esporte, com evidência para os treinadores da modalidade, que cumpriram uma ação relevante no processo de introdução destas atletas no esporte paralímpico.

O artigo de João Manuel Casquinha Malaia Santos e Sérgio Settani Giglio tem como objetivo efetivar um debate historiográfico sobre a pesquisa em história do esporte e, em particular, sobre o passado dos Jogos Olímpicos Modernos a partir da apresentação de um panorama sobre a produção internacional e nacional, nas últimas décadas, neste campo de estudo. Analisando os registros de bases de dados no Brasil e 
Dossiê | Apresentação do dossiê "Jogos Olímpicos e Paralímpicos na contemporaneidade: uma breve revisão literária da produção científica vigente” (PEREIRA, Ester Liberato Pereira; CANCELLA, Karina Barbosa Cancella; MEDEIROS, Jimmy)

no exterior, os autores efetivaram um levantamento de livros, artigos, dissertações e teses que versavam sobre as temáticas de interesse. Em suas considerações, os autores apontam que, apesar de ser possível registrar um crescimento no número de produções, inclusive com revistas científicas, grupos de estudos e eventos com foco específico na história do esporte e do movimento olímpico, ainda há uma distância importante entre a produção nacional e internacional, categorizada por Santos e Giglio como um "vazio historiográfico no que se refere à produção de pesquisa no Brasil sobre o passado dos Jogos Olímpicos".

Como se pode notar, ao fim dessa pequena introdução ao dossiê, a riqueza do campo dos Estudos Olímpicos e Paraolímpicos está nas possibilidades vastas e variadas que nossos objetos de estudos - o Olimpismo e os Esportes Olímpicos e Paraolímpicos sob uma perspectiva multidisciplinar - permitem aos que ousam a despir seus problemas, a compreender seus obstáculos, seus contrassensos; as causas e porquês da adoção de determinados caminhos e não de outros; as possibilidades nas quais temos, ainda, para empreender.

Contudo, e especialmente, nossa procura, enquanto campo científico, é por dotar os intérpretes do Olimpismo e dos Esportes Olímpicos e Paraolímpicos com as ferramentas e instrumentos imprescindíveis para esta tarefa, retomando aquilo que existe de comum nos aspectos históricos, culturais, sociais e filosóficos do Olimpismo e do esporte, bem como em suas dimensões políticas e de gestão.

No momento atual, com a chegada da pandemia, tais reflexões fazem-se ainda mais imperativas e imprescindíveis para encarar a vindoura reinvenção de um novo contexto esportivo mundial.

\section{Referências}

DACOSTA, Lamartine Pereira. Estudos Olímpicos no Brasil. In: RUBIO, Katia; REPPOLD FILHO, Alberto; TODT, Nelson; MESQUITA, Roberto. Ética e compromisso social nos estudos olímpicos. Porto Alegre: EDIPUCRS, 2007, p. 91- 101.

GUERREIRO, Renato de Carvalho et al. Was postponing the Tokyo 2020 Olympic and Paralympic Games a correct decision? Revista Brasileira de Medicina do Esporte, São Paulo, v. 26, n. 3, p. 191-195, Jun/2020. Disponível em: 
Dossiê | Apresentação do dossiê "Jogos Olímpicos e Paralímpicos na contemporaneidade: uma breve revisão literária da produção científica vigente” (PEREIRA, Ester Liberato Pereira; CANCELLA, Karina Barbosa Cancella; MEDEIROS, Jimmy)

<https://www.scielo.br/pdf/rbme/v26n3/1806-9940-rbme-26-03-0191.pdf>. Acesso em: 11 jun. 2020.

GASTALDO, Edison. Sobre os estudos sociais do esporte: políticas acadêmicas de um campo em desenvolvimento. In: 35 Encontro da ANPOCS, Caxambú/MG, 2011.

GIGLIO, Sérgio Settani; AMARAL, Silvia Cristina Franco; RIBEIRO, Olívia Cristina Ferreira; BORTOLETO, Marco Antonio Coelho (org.). Múltiplos olhares sobre os Jogos Olímpicos. São Paulo: Intermeios; Fapesp, 2018.

IOC. The Olympic Charter. Lausanne, 2010.

MARQUES, José Carlos; ROCCO JÚNIOR, Ary José (orgs.). Qual legado - Leituras e Reflexões sobre os Jogos Olímpicos Rio-2016/E-book. São Paulo: Cultura Acadêmica, 2018.

MARQUES, Renato Francisco Rodrigues; DUARTE, Edison; GUTIERREZ, Gustavo Luis; ALMEIDA, José Júlio Gavião; MIRANDA, Tatiane Jacusiel. Esporte olímpico e paraolímpico: coincidências, divergências e especificidades numa perspectiva contemporânea. Revista Brasileira de Educação Física e Esporte, São Paulo, v.23, n.4, p.365-77, out./dez. 2009.

MASCARENHAS, Fernando. Megaeventos esportivos e educação física: alerta de tsunami. Movimento (ESEFID/UFRGS), Porto Alegre, p. 39-67, jan. 2012. Disponível em: $<$ https://seer.ufrgs.br/Movimento/article/view/25260/17340>. Acesso em: 02 jul. 2020.

PILZ, Gunter A.. Sociologia do Esporte na Alemanha. Revista Estudos Históricos, Rio de Janeiro, v. 13, n. 23, p. 3-16, jul. 1999. Disponível em: $<$ http://bibliotecadigital.fgv.br/ojs/index.php/reh/article/view/2090>. Acesso em: 02 Jul. 2020.

RUBIO, Katia; REPPOLD FILHO, Alberto; TODT, Nelson; MESQUITA, Roberto. Ética e compromisso social nos estudos olímpicos. Porto Alegre: EDIPUCRS, 2007.

TAVARES, Otávio; BELÉM, Cristiano; GODOY, Letícia; TURINI, Marcio; GOMES, Marta; TODT, Nelson. Estudos olímpicos, Academia Olímpica Brasileira - Educação Olímpica. In: DACOSTA, Lamartine Pereira (org.). Atlas do Esporte no Brasil: atlas do esporte, educação física a atividades físicas de saúde e lazer no Brasil. Rio de Janeiro: Shape, 2005, p.751-753.

TAVARES, Otávio. Quem são os vencedores e os perdedores dos Jogos Olímpicos? Pensar a Prática, Goiânia, v. 8, n. 1, p. 69-84, 2005. 